\title{
ANALYZING AREAL PRECIPITATION AT KEY BASINS IN COCHABAMBA USING SATELLITE- BASED PRECIPITATION
}

\author{
Andrés G. Vallejos, Samuel A. Ancalle, Ana C. Escalera and Oliver C. Saavedra
}

\begin{abstract}
Monitoring spatial precipitation at high resolution is a crucial variable in semi-arid regions like Cochabamba city. However, limitations regarding the number, quality and uniform distribution of operating rain gauges inside the basin's area, lead us to examine data and combine it with satellite-based precipitation. These products' accuracy is increasing, but their evaluation needs validation before its usage in water balance. We focused in the five key basins that may provide water for agriculture and drinking purposes in metropolitan area of Cochabamba city (Cbba). A three level comparison was carried out, considering hourly and daily values of precipitation intensities measured at available stations, areas of influence and sub basins. Accumulated monthly values from Global Satellite Mapping of Precpitation (GSMaP) data correlate better than a comparison with Servicio Nacional de Meteorología e Hidrología SENAHMI's daily measures. The results showed spatial and temporal variability between GSMaP and SENAHMI stations. Actually, it is important to point out that in most cases; values estimated by GSMaP's became underestimated when compared against surface gauges. Hence, we propose a simple integration method of gaugebased and satellite-based precipitation data, using correction factors. We reached a $19 \%$ improvement of areal precipitation for the rainy season 2015/2016, using correction factors obtained by correlating data from SENAMHI and GSMaP and evaluating the relative errors during previous rainy season 2014/2015. Subsequently, we plan to apply them as input to hydrological models to obtain river discharge values and determine whether the fulfilment of water demand in Cbba is possible. In future studies we plan to include the potential climate change scenarios and adjust precipitation variability according to elevation range which is 2500-3500 m.a.s.l. in this region. Results are expected to provide a higher resolution of precipitation, also produce more accurate water balance to support wise decisions over the water resources management in semi-arid regions.
\end{abstract}

Keywords: Cochabamba, Bolivia, GSMaP, Satellite-Based-Precipitation, Water Supply. 